\title{
UMA ANÁLISE DE COMO O AMBIENTE INFLUÊNCIA NA APRENDIZAGEM E NO COMPORTAMENTO DE ESTUDANTES SUA IMPORTÂNCIA NA FORMAÇÃO INICIAL DE PROFESSORES
}

\author{
UNA ANALISIS DE COMO EL AMBIENTE INFLUENCIA EN EL APRENDIZAJE Y \\ EN EL COMPORTAMIENTO DEL ALUMNO Y SU IMPORTANCIA EN LA \\ FORMACIÓN INICIAL DE PROFESORES
}

\section{AN ANALYSIS OF AS THE ENVIRONMENT INFLUENCE IN THE LEARNING AND THE BEHAVIOR OF THE STUDENT AND ITS IMPORTANCE IN THE INITIAL TEACHER TRAINING}

\author{
Elaine das Graças FRADE ${ }^{1}$ \\ Yara Rosa Romanelli Campos Gonçalves da SILVA ${ }^{2}$ \\ Jessiane LOPES $^{3}$
}

RESUMO: O trabalho apresentado trata-se de um relato de experiência a respeito de atividade realizada no horto medicinal da Universidade Federal de Lavras, referente a disciplina de Psicologia da Educação em uma de suas aulas. Objetiva-se compreender e analisar como o ambiente pode proporcionar benefícios para os estudantes, e a sua importância na formação inicial de professores. Para analisar os resultados obtidos, utilizou-se a pesquisa qualitativa, para uma melhor organização, foi utilizado o método de categorização onde foram encontradas quatro categorias: "Atividade vista como metodologia diferente da tradicional"; "maior participação do estudante e a mesma sendo em um ambiente que difere da sala de aula"; "a fim de aumentar os laços na relação estudante-educadora" e "uma forma de conhecer melhor o estudante". O trabalho buscou compreender como metodologias diferentes são eficazes e auxiliam na formação da pessoa, e como esses meios interdisciplinares auxiliam no conhecimento e compreensão mais eficaz de mundo.

PALAVRAS-CHAVE: Atividades educativas. Formação inicial de professores.

Metodologias diferentes. Psicologia da educação.

RESUMEN: El trabajo presentado se trata de un relato de experiencia acerca de una actividad realizada en el huerto medicinal de la Universidad Federal de Lavras, referente a la disciplina de Psicología de la Educación en una de sus clases. Objetivos comprender y analizar cómo el ambiente puede proporcionar beneficios para los estudiantes, y su importancia en la formación inicial de profesores. Para analizar los resultados obtenidos, se

${ }^{1}$ Universidade Federal de Lavras (UFLA), Lavras - MG - Brasil. Professora Adjunta do Departamento de Educação. Doutora em Ciências. ORCID: http://orcid.org/0000-0001-7095-9426. E-mail: elaine.frade@ufla.br ${ }^{2}$ Universidade Federal de Lavras (UFLA), Lavras - MG - Brasil. Graduanda em Ciências Biológicas. ORCID: http://orcid.org/0000-0002-7611-3162.E-mail: yararom12@ hotmail.com

${ }^{3}$ Universidade Federal de Lavras (UFLA), Lavras - MG - Brasil. Graduanda em Ciências Biológicas na Universidade Federal de Lavras. ORCID: http://orcid.org/0000-0002-9777-4621. E-mail: jessiannelopess@hotmail.com 
utilizó la investigación cualitativa, para una mejor organización, se utilizó el método de categorización donde se encontraron cuatro categorías: "Actividad vista como una metodología diferente de la tradicional"; "mayor participación del estudiante y la misma siendo en un ambiente que difiere del aula"; "a fin de aumentar los vínculos en la relación estudiante-educador" y "una forma de conocer mejor al estudiante". El trabajo busco comprender cómo metodologías diferentes son eficaces y auxilian en la formación de la persona, y cómo esos medios interdisciplinarios auxilian en el conocimiento y la comprensión más eficaz del mundo.

PALABRAS CLAVE: Actividades educativas. Formación inicial de profesores. Metodologías diferentes. Psicología educativa.

ABSTRACT: The present work is an experience report about an activity carried out in the medical horticulture of the Federal University of Lavras, referring to the discipline of Educational Psychology in one of its classes. The work in question aims to understand and analyze how the environment can provide benefits for students, and their importance in initial teacher training. In order to analyze the obtained results, we used the qualitative research, which approaches the direct proximity of the researcher, for a better organization, the categorization method was used where four categories were found: "Activity seen as a methodology different from the traditional one"; "student participation and the same being in an environment that differs from the classroom"; " increase the ties in the student-educator relationship" and" "way to get to know the student better". The work seeks to understand how different methodologies are effective and help in the formation of the person, and how these interdisciplinary means help in the most effective knowledge and understanding of the world.

KEYWORDS: Educational activities. Initial teacher training. Different methodologies. Environment. Educational psychology.

\section{Introdução}

Reconhece-se que a formação inicial de professores está muito além da conquista de "habilidades tecnicomecânicas" visto que lecionar não é uma ação "burocrática", mas um empreendimento intelectual de criticidade e reflexão sobre o contexto educacional e social. .A formação docente ancora-se no princípio da apropriação do conhecimento pelos estudantes e no ensino-aprendizagem de forma mais ampla (PIMENTA, 1996). Nessa perspectiva as instituições de ensino precisam formar seu corpo docente com professores qualificados capazes de buscar metodologias e esferas inovadoras e dar-lhes apoio necessário para que o façam com autonomia afim de potencializar o aprimoramento do conhecimento dos estudantes. Ademais, Tapia e Fita (2003, p. 88) afirmam que se persiste a desmotivação do professor, se o mesmo não exerce de forma satisfatória sua profissão, o reflexo é apenas estudantes desinteressados com as tarefas escolares. 
Desse modo, a utilização de metodologias diferentes das tradicionais é uma das alternativas encontradas pelos professores para que um conteúdo seja abordado de uma forma diferente da tradicional, e o estudante possa adquirir o conhecimento de um modo mais atrativo e cativante, onde o mesmo perceba a importância de determinado conceito e como o mesmo é presente ou inserido na sua realidade.

Para Gasparin e Petenucci (2014), a escolha de uma determinada metodologia a ser utilizada contribui muito para o sucesso ou fracasso do processo ensino-aprendizagem. Portanto, um dos caminhos para conquistar a atenção das pessoas em processo de aprendizagem é empregar metodologias baseadas em aspectos lúdicos despertando o interesse do estudante na aula ou em ambientes que diferem a quatro paredes "comuns" e recorrentes da sala de aula.

A teoria cognitiva contribui no processo para uma aprendizagem significativa, pois visa compreender, transformar e armazenar as informações cognitivas. Para Ausubel (1993), a essência deste processo está vinculada as ideias simbolicamente expressas de maneira substantiva e não absolutista, ou seja, a algo que o aprendiz já tenha conhecimento, como uma imagem, um símbolo ou um conceito. No entanto a educação que dominada no atual contexto escolar, é a denominada mecanizada, onde a mesma não averigua conhecimentos preexistentes, dessa forma, o novo conhecimento pode ser reproduzido, mas não aprimorado tornando-se insignificante para o estudante.

Portanto, pensando em atributos capazes de contribuir na reestruturação da educação atual as aulas desenvolvidas em diferentes ambientes têm sido de suma importância e eficaz tanto por envolverem e motivarem crianças e jovens nas atividades educativas, quanto por constituírem um instrumento de superação da fragmentação do conhecimento (SENICIATO, 2004).

O pressuposto inferido aqui, é que a utilização de metodologias e abordagens inovadoras são capazes de desconstruir a ideia tradicional de aprendizagem somente na sala de aula em que o professor é detentor de todo conhecimento sendo está sua única função, tendo como consequência um distanciamento do educando/educador, tornando-se algo hierarquizado.

Assim, na concepção de Lopes e Allain (2002) para que tais atividades sejam bemsucedidas é fundamental que o professor esteja bem preparado e saiba estabelecer objetivos claros, visto que os estudantes estão sujeitos a uma quantidade maior de fenômenos quando comparada a uma aula tradicional, o que pode confundi-los na construção dos conceitos. 
Em consonância com formas diferentes de lecionar uma aula, outro atributo que aprimora o conhecimento do estudante, é introduzir os temas transversais que possibilitam em determinada aula a compreensão da realidade do mundo. De Macedo (1999), o documento PCN (Parâmetros Curriculares Nacionais) que traz os temas transversais, e como os mesmos podem ser trabalhados e como podem ser encaixados nos espaços curriculares disciplinares em que se melhor se adaptarem com a ajuda do professor, fazendo com que assim ajude o estudante a correlacionar os temas abordados com questões do cotidiano, e na sua formação como cidadão ativo.

Desse modo, a atividade realizada na disciplina de Psicologia da Educação, da Universidade Federal de Lavras, aponta alguns indicadores de benefícios do aprendizado do estudante, destaca a importância de aulas em ambientes diversificados, contribuindo para o reconhecimento de que tais atividades são de fato mais relevantes e motivadoras, além de auxiliarem na aprendizagem dos conhecimentos científicos e estimular a coletividade firmando a relação educando/educador, à medida que possibilitam uma visão mais ampla e dinâmica, e como também a mesma contribuiu para formação inicial de professor.

\section{Desenvolvimento}

A atividade analisada ocorreu em uma aula da disciplina de Psicologia da Educação, da Universidade Federal de Lavras- UFLA ofertada para os cursos de licenciatura em Ciências Biológicas e Educação Física, proposta em um espaço diferente da sala de aula, sendo assim, realizada no horto medicinal da UFLA.

A atividade se baseava em conhecer o local e como as plantas presentes ali tinha uma finalidade e uso, sendo para chás, remédios e afins. O ponto inicial da atividade, que com ajudada da monitora do local, a princípio foi um breve passeio no horto, no qual os participantes tiveram a oportunidade de explorar o local, conhecendo as plantas, suas utilizações na medicina e culinária, aprimorando os conhecimentos emitidos pela instrutora.

Em seguida, os participantes se reuniram para uma roda de conversa em que refletiram sobre o passeio e como o mesmo tinha relação com os textos: "Corpo, Mídia e Educação Física, de Marlene Vitória Biscaro"; "Um olhar sobre o corpo: o corpo ontem e hoje, de Maria Raquel Barbosa"; "Paradigmas da Psicologia aplicada a educação, de Mércia Moreira" e o filme "O Quarto de Jack" do diretor Lenny Abrahamson, 2010 ressaltados em aulas anteriores, gerando assim discussões construtivas baseadas no tema: Construção do Corpo dialogando com a vivência realizada no horto.. 
Durante a discussão foram destacando nomes como Vygotsky, Wallon e Piaget que trouxeram grandes contribuições e que com essa interação se faz efetivo o processo educativo, uma vez que é no coletivo que os sujeitos apropriam dos conhecimentos, e ressaltando que esse tipo de contato é essencial para estabelecer um movimento de conexão entre a realidade escolar e a realidade do mundo que é vivenciada pelos estudantes, assim, fazendo da escola um local de troca de vivências.

Ao final da atividade, foi realizado como um método de confraternização, um piquenique cujo os alimentos ali presentes foram os próprios estudantes que levarem e compartilharam uns com os outros colaborando para a proximidade e o prazer de todos os envolvidos. E por fim, foi pedido para que os estudantes escrevessem uma frase ou um texto ressaltando de "Como a atividade realizada no Horto Medicinal, contribuiu para sua formação inicial de professor?", fazendo com que assim finalizasse a atividade proposta.

\section{Metodologia}

Para observarmos com a prática desenvolvida durante a atividade teve sua importância e como a mesma influência na formação docente, foi realizada uma avaliação com os participantes, onde os mesmos relataram como a atividade presenciada no horto medicinal, foi importante para sua formação inicial de professor. Nesse contexto, foi utilizada a análise da pesquisa qualitativa, onde a mesma busca interpretar o fenômeno estudado.

Para analisar os resultados dentro da pesquisa qualitativa adotou-se o processo de análise de conteúdo, onde que por meio da categorização, permite-se agrupar falas de comum acordo de alunos, onde estas sintetizam e expressam os mesmos sentimentos (MINAYO, 2002), facilitando assim a compreensão e a maior facilidade de estudo das mesmas.

\section{Resultados e Discussões}

Tabela abaixo encontram-se as cinco categorias encontradas de acordo com analises das avaliações:

Quadro1 - Categorias, descrição e frequência 


\begin{tabular}{|c|c|c|}
\hline Categoria & Descrição & Frequência \\
\hline $\begin{array}{l}\text { Atividade vista como uma metodologia } \\
\text { diferente da } \\
\text { tradicional }\end{array}$ & $\begin{array}{l}\text { Ressalta como os alunos viram a } \\
\text { atividade como um método diferente } \\
\text { para se lecionar uma aula. }\end{array}$ & 18 \\
\hline $\begin{array}{l}\text { Atividade proporcionando uma maior } \\
\text { participação do estudante e a mesma } \\
\text { sendo em um ambiente que difere da } \\
\text { sala de aula }\end{array}$ & $\begin{array}{l}\text { Demonstra como a mesma } \\
\text { proporcionou uma maior } \\
\text { participação dos alunos e interesse dos } \\
\text { mesmos pela a aula, já que a aula } \\
\text { ocorre em ambiente diferente. }\end{array}$ & 16 \\
\hline $\begin{array}{l}\text { Atividade a fim de aumentar os } \\
\text { laços na relação educando-educador }\end{array}$ & $\begin{array}{l}\text { Analisa como atividade contribui } \\
\text { para quebrar a barreira que se tem } \\
\text { entres aluno e o professor, } \\
\text { aumentar e essa } \\
\text { proximidade. }\end{array}$ & 10 \\
\hline $\begin{array}{l}\text { Atividade como uma forma de } \\
\text { conhecer melhor o estudante }\end{array}$ & $\begin{array}{l}\text { Analisa como o ambiente auxilia na } \\
\text { forma de conhecer melhor o estudante, } \\
\text { que está situado fora do ambiente } \\
\text { escolar. }\end{array}$ & 8 \\
\hline
\end{tabular}

Fonte: Autoras

A primeira categoria traz como a atividade foi vista pelos estudantes como uma forma de metodologia diferente, a mesma com frequência 18, ressalta como é importante a prática de metodologias diferentes das tradicionais em ambientes escolares, recurso este utilizados com pouco frequência em salas de aulas, e que induzem a maioria dos professores a recorrerse de métodos tradicionais simplistas.

A educação formal, é uma educação bastante presente sistema brasileiro ainda em sua atualidade, onde se baseia em um processo onde as aulas são lecionadas em ambientes fechados, com quadro negro e uma deposição conteudista de determinado assunto. Esse tipo de ensino mecanizado, onde o estudante se sente preso a quatro paredes, sem posição para 
argumentar, e sendo desanimado com o método que presencia todos os dias, acaba levando-o ao enorme desinteresse por estudar, conhecer algo novo, e se socializar por assuntos de ambiente acadêmico, fazendo-se assim com que esse modelo acabe não sendo eficaz.

Assim, em contraposição com esse modelo educacional, trazemos a educação não formal, onde está se contraria de todos os modos, o sistema anterior. A educação não-formal, se entende por uma proposta de tentativa educacional organizada e sistemática que, se realiza em locais fora do sistema formal de ensino. Nesse sentido, a atividade realizada no Horto Medicinal, da Universidade Federal de Lavras, onde por meio da atividade proposta durante a disciplina de Psicologia da educação, nos mostra como esses tipos de espaços podem ser utilizados como abordagem de assuntos a serem ensinados, introduzindo os alunos em uma ambiente que defere da sala de aula e se torna mais atrativo e eficiente para o aluno.

$\mathrm{Na}$ segunda categoria com frequência 16, os estudantes citaram como a atividade proporcionou uma maior participação e interesse dos participantes, de modo que houvesse maior apresso pelo tema a ser aprendido, já que o modo do qual estava sedo ensinado, era em um local diferenciado do costume que possuíam- a sala de aula.

Ao introduzir o estudante em um ambiente que estimule sua criatividade e vontade do saber, é de extrema importância para sua formação, uma vez que o mesmo consegue perceber que em todos os tipos de esferas e âmbito, ele pode adquirir um conhecimento completo e que atinge a catarse de modo que o conhecimento adquirido seja incorporado e integrado em seu meio social, já que o aluno é um cidadão que compõe a sociedade.

Para reafirma os conceitos acima, segue falas encontradas na avaliação dos estudantes participantes que reforçam essa ideia:

A1: "Creio que a experiência no horto proporcionou maior interesse em relação ao conhecimento e maior participação dos alunos. Acredito que o ambiente que foi proposta a aula, influência bastante na aprendizagem”.

A2: "... faz pensar na importância da interação dos alunos com o meio, e como a quebra da rotina já desperta o interesse dos alunos para com os assuntos”.

A3: “...há diversas maneiras de se ministrar uma aula, fugindo do contexto de modelo de aula tradicional, e que quando essa fuga acontece, na maioria das vezes os alunos se mostram mais interessados e dispostos a participarem das aulas e interagir com a aula em si..." 
Com frequência 10, a terceira categoria discute como a atividade proporcionou uma maior relação e proximidade do estudante com o professor. Sabemos que por influência do sistema educacional que esteve e ainda está bastante presente na educação brasileira, o professor e o estudante sempre tiveram uma relação distante, onde o professor é o mediador, aquele que detém o conhecimento que será passado para o aluno, e o pupilo é quem recebe este conhecimento, mas todo esse processo sem troca de saberes.

Uma das grandes problemáticas que dificulta o ensino brasileiro, é a falta proximidade entre as pessoas durante os processos educativos. $\mathrm{O}$ estudante ele vê o professor com uma barreira que impede o mesmo de expor suas opiniões e dúvidas obtidas durante uma aula; essa barreira se dá pelo fato de grande parte dos professores, adotarem a forma "tradicional" de se ensinar uma aula, onde tudo o que o mesmo diz, se torna para o aluno o verídico, a verdade, sobre determinado assunto ali disposto.

Ao propor a aula no horto, os estudantes viram o professor de uma forma diferente, pois aquele que em sala de aula, que se dispunha de todo o conhecimento ou de grande parte; agora no "novo" ambiente, ele era similar aos seus estudantes, de modo que como o local foi apresentado pela monitora do horto, uma pessoa capacitada para discutir sobre as plantas e suas funções distintas, a mesma era que naquele ambiente detinha todo o conhecimento para ser repassado, e assim, o professor se tornou também estudante na mesma posição que os demais, estava disposto a aprender algo novo, quebrando assim essa distância que eles tinham em sala de aula.

As falas dos estudantes reforçam o tópico discutido:

A3: “..., na maioria das vezes os alunos se mostram mais interessados e dispostos a participarem das aulas e interagir com a aula em si, reforçando a necessidade dos professores renovarem suas maneiras de trabalhar, buscando formas de aproximação com seus alunos".

A4: "As atividades serviram para criar uma relação com os alunos e professores fora de sala enriquecedor, por ser atividades diferentes e que passam conhecimento".

A5: “... Esse tipo de atividade aproxima o professor dos alunos e proporciona uma vivência pessoal interessante".

Na última categoria com ocorrência 8 , ela vem discutir como dinâmicas propostas por professores que se desafiam a levar seus estudantes para um ambiente fora de sala de aula - 
ambiente estes capaz de suprir todos os requisitos para um aprendizado completo-, eles proporcionam uma melhor forma de conhecer o aluno.

Quando o discente se depara com locais que ele se sente mais à vontade e livre para expressar suas opiniões, ideias e se relacionar com as pessoas ao seu redor, podemos observar que o comportamento deste se difere da sala de aula, local onde se sente acuado e sem liberdade de ser quem realmente é. Deste modo, o horto ele vem com a proposta de fazer com que o discente se adere e sinta parte do contexto que está ali inserido, de forma que ele possa absorver e construir um conhecimento mais significativo para ele próprio, podendo expressar suas vontades sem se delimitar.

Nesse sentido, o professor pode conhecer mais o estudante que está presente com ele durante a semana, esse conhecimento podendo ser de forma, mas individual, ou coletiva junto com os colegas de sala. O professor ele procurará conhecer o estudante como uma síntese individual ou da interação desse sujeito, abordando em conjunto seu meio cultural, político, econômico e educacional. Quando o professor tem a oportunidade de conhecer melhor sua turma, o mesmo pode se aderir de artefatos para que sua aula seja mais atrativa e eficaz, para estes alunos com um determinado perfil.

\section{Considerações finais}

O trabalho discutiu como é possível a realização de aulas em locais diferentes e fora do ambiente monótono da sala de aula, e como estas atividades nos permitem observar e analisar como o estudante é capaz de aprender de forma eficaz e relevante um determinado conteúdo, através de uma simples conversa de troca de conhecimento e saberes.

O mesmo ressaltou como o ambiente tem grande influência nessa aprendizagem e no modo de comportamento e expressão do aluno ali inserido, contemplando-o a um olhar e aproximação mais amplo ao próximo, principalmente com o professor, uma vez que estes locais mais descontraídos priorizam e auxiliam na quebra de barreiras que datam o professor e o aluno, os aproximando-os cada vez mais.

A experiência e atividade realizada no horto contribui para todos esses eixos e olhares mais amplos, possibilitando também uma apropriação de conceitos e conhecimentos que auxiliaram de forma relevante para a formação inicial de professores. 


\section{REFERÊNCIAS}

AUSUBEL, D. Teoria da aprendizagem significativa. In: PELIZZARI, A. et al., 1993.

CAVASSAN, O. Aulas de campo em ambientes naturais e aprendizagem em ciências: um estudo com alunos do ensino fundamental. Ciência \& Educação (Bauru), p. 133-147, 2004.

MACEDO, E. F. de. Parâmetros Curriculares Nacionais: a falácia de seus temas transversais. In: MOREIRA, A. F. B. Currículo: políticas e práticas, 1999. p. 43.

GASPARIN, J. L.; PETENUCCI, M. C. Pedagogia histórico crítica: da teoria à prática no contexto escolar. 2014.

LOPES, G. C. L. R.; ALLAIN, L. R. Lançando um olhar crítico sobre as saídas de campo em biologia através do relato de uma experiência. ENCONTRO "PERSPECTIVAS DO ENSINO DE BIOLOGIA”, v. 8, p. 6, 2002. In: MINAYO, M. C. S. (org.). Pesquisa social: teoria, método e criatividade. 21. ed. Petrópolis/RJ: Vozes, 2002.

MINAYO, M. C. S. (Org.). Pesquisa social: teoria, método e criatividade. 21. ed. Petrópolis/RJ: Vozes, 2002.

PIMENTA, S. G. O estágio na formação de professores: Unidade teoria e prática? 4. ed. São Paulo: Cortez, 2001.

SENICIATO, T.; CAVASSAN, O. Aulas de campo em ambientes naturais e aprendizagem em ciências: um estudo com alunos do ensino fundamental. Ciência \& Educação (Bauru), p. 133-147, 2004

TAPIA, J. A. Contexto, motivação e aprendizagem. In: TAPIA, J. A.; FITA, E. C. A motivação em sala de aula: o que é, como se faz, v. 4, p. 11-61, 2004.

\section{Como referenciar este artigo}

FRADE, E. das G.; SILVA, Y. R. R. C. G. da; LOPES, J. Uma análise de como o ambiente influência na aprendizagem e no comportamento dos estudantes e sua importância na formação inicial de professores. Doxa: Rev. Bras. Psico. e Educ., Araraquara, v. 21, n. 1, p. 78-87, jan./jun. 2019. e-ISSN: 2594-8385. DOI: https://doi.org/10.30715/doxa.v21i1.12879

Submetido em: $10 / 09 / 2018$

Aprovado em: 30/11/2018

Publicado em: 01/02/2019 